\title{
Behavior of rock wool in lungs after exposure by nasal inhalation in rats
}

\author{
Yuichiro Kudo $\cdot$ Yoshiharu Aizawa
}

Received: 13 October 2008/Accepted: 16 February 2009/Published online: 26 May 2009

(C) The Japanese Society for Hygiene 2009

\begin{abstract}
To evaluate the safety of rock wool (RW fibers), we examined the biopersistence of a RW sample in the lungs of rats, based on the changes of fiber number and fiber size in terms of length and width, by a nose-only inhalation exposure study. Twenty male Fischer 344 rats (6-10 weeks old) were exposed to RW fibers at a concentration of 70 (21) fiber $/ \mathrm{m}^{3}$ and $30(6.6) \mathrm{mg} / \mathrm{m}^{3}$, arithmetic mean (geometric standard deviation), continuously for $3 \mathrm{~h}$ daily for five consecutive days. Five rats each were sacrificed shortly and at 1,2, and 4 weeks after exposure, and their lung tissues were ashed by a low-temperature plasma-asher. Then, the numbers and sizes of fibers in the ashed samples were determined using phase-contrast microscope and computed image analyzer. The fiber numbers in the lungs 4 weeks after exposure significantly decreased from the baseline value, i.e., shortly after exposure $(P<0.05)$. The half-lives of RW fibers calculated from the one-compartment model were 32 days for total fibers and 10 days for fibers longer than $20 \mu \mathrm{m}$. The decrease of fiber number was $53.6 \%$ by 4 weeks after exposure (baseline group $=100 \%$ ). Likewise, fiber sizes significantly decreased by 4 weeks after exposure $(P<0.05)$, probably because fibers were dissolved in body fluid, ingested by alveolar macrophages or discharged to outside of the body by mucociliary movement. In future studies, it is necessary to examine the long-term persistence of RW fibers in the lungs.
\end{abstract}

Y. Kudo $(\bowtie) \cdot$ Y. Aizawa

Department of Preventive Medicine and Public Health,

Kitasato University School of Medicine,

1-15-1 Kitasato, Sagamihara, Kanagawa 228-8555, Japan

e-mail: yuichiro@med.kitasato-u.ac.jp
Keywords Rock wool · Nose-only inhalation · Clearance $\cdot$ Biopersistence

\section{Introduction}

Asbestos excels in heat resistance, insulation performance, and durability and has been used for building construction materials such as asbestos cement products, cement boards, reinforcing material for synthetic resin such as vinyl flooring, board, and gear, spray-coating material for heat or sound insulation, and heat insulation material for boiler pipes, furnaces, etc. However, it has been reported to cause fibrosing lung disease, lung cancer, and malignant mesothelioma of the pleura and peritoneum [1-3], and proved to have toxicity through many in vitro and in vivo experiments. Therefore, the use of asbestos has been banned or restricted all over the world [4-6]. In Japan, the Enforcement Order of the Industrial Safety and Health Law, Industrial Safety and Health Regulations, and Ordinance on Prevention of Hazards due to Specified Chemical Substances were revised in 1995 to ban the manufacture, import, use, and sale of amosite and crocidolite, and products containing either of them at a level exceeding $1 \%$. In addition, the manufacture, import, use, and sale of chrysotile and products containing chrysotile at a level exceeding 1\% have been banned since October 2004 . Under these circumstances, the related industries are facing an urgent need to develop a safer fibrous substance as an asbestos substitute.

In the current market, various kinds of manmade vitreous fibers (MMVF) have been used as asbestos substitutes. Rock wool (RW), a kind of MMVF, is made from molten soft slag such as iron slag, copper slag, nickel slag, etc., and natural stone, such as andesite, basalt and amphibolite. 
Because RW excels in heat resistance, fire resistance, and sound absorption, it is mainly used as a fire- and heatresistant material, heat insulation material, and sound absorption material [7]. In previous study of in vivo experiments using RW, lung fibrosis was observed in rats, but the development of lung tumors was not reported [8], and $\beta$-glucuronidase and lactate dehydrogenase (LDH) released from macrophages [9] and giant cell formation of cultured cells [10] were reported, although such effects of RW were weaker than those of chrysotile. Based on these studies, the International Agency for Research on Cancer (IARC) classifies RW as group 3: limited or immature carcinogenicity in animals, and unclassifiable carcinogenicity in humans [11].

To evaluate the biological effects of MMVF such as RW, many studies of in vivo experiments have been performed, including short- and long-term inhalation exposure, injection of MMVF into the pleura and peritoneum, and injection into the trachea. Reports by the IARC [11] have proved that inhalation exposure studies are the most suitable method to evaluate effects on public health.

In the present study, to examine the persistence of RW in the lungs as an index of the effect of RW on the respiratory system, we conducted a short-term nose-only inhalation exposure study in rats.

\section{Materials and methods}

\section{Materials}

As an analyte material, we used a RW sample manufactured by NC Co. Ltd., Japan, provided by the Rock Wool Association, Japan. Fluorescent X-ray spectroscopy showed that the RW sample was chemically composed of $39 \% \mathrm{SiO}_{2}, 33 \% \mathrm{CaO}, 14 \% \mathrm{Al}_{2} \mathrm{O}_{3}, 5 \% \mathrm{MgO}, 1.8 \% \mathrm{Fe}_{2} \mathrm{O}_{3}$, and $0.6 \% \mathrm{~S}$.

Originally, RW is present in the form of lumps of fibers of different sizes (length and width). In general, animal experiments are conducted to evaluate the biological effects of MMVF. Because the biological effect of fibers is known to vary depending on the size, the fiber size is important to know the maximum harmful effect. Therefore, we adjusted the size of RW in accordance with the method by Kohyama [12], that is, bulk RW was filled into a cylinder $\left(6 \mathrm{~cm}\right.$ diameter, $\left.28.3 \mathrm{~cm}^{2}\right)$, and a pressure of $160 \mathrm{~kg}$ / $\mathrm{cm}^{2}$ (4.5 MPa) was applied twice using a manual oil press machine (type BRM 32, Maekawa MFG Co., Ltd., Tokyo). Raw fibers of RW were pulverized into shorter fibers by this process, and the pulverized shorter fibers were used for the present inhalation experiment. The sizes of pulverized RW fibers dispersed in the exposure chamber were measured by sampling, using a filter method and electron microscopy. Their geometric mean length (geometric standard deviation) and geometric mean width (geometric standard deviation) were $15.49(2.02) \mu \mathrm{m}$ and 2.44 (1.59) $\mu \mathrm{m}$, respectively (Fig. 1). Then, to make it easier to generate RW in the nose-only inhalation exposure system, the pulverized RW fibers were mixed with glass beads (BZ-02, AS ONE Corp., Osaka) at a ratio of 1 (RW) to 39 (glass beads) by weight.

Nose-only inhalation exposure system

The materials prepared according to the above procedure were treated as follows: air was supplied from an air compressor to a material generator, as reported by Kudo et al. [13], at a rate of $30 \mathrm{~L} / \mathrm{min}$, and the materials were placed in the material storage tank of the material generator. The materials mixed with glass beads were fluidized by air from the air compressor, and separated from the glass beads. As a result, the materials were emitted into the air. The generated materials were sent to the subchamber, diluted with filtered air to a specified concentration, and transferred to the exposure chamber. The exhaust flow rate in the exposure chamber was set at $40 \mathrm{~L} / \mathrm{min}$. To maintain the concentration of RW fibers $(10,000 \mathrm{cpm})$ in the exposure chamber, the concentration was monitored using a digital dust meter, and the amount of materials to be generated was adjusted by applying feedback to the feeder. The rat holders were placed in the exposure chamber.

Exposure study

Ten male Fischer 344 rats (6-10 weeks old) were used for each experiment, and each experiment was performed twice (20 rats in total). To acclimatize the rats to the environment of the laboratory, they were first housed in cages for 1 week with free access to water, food, and fresh

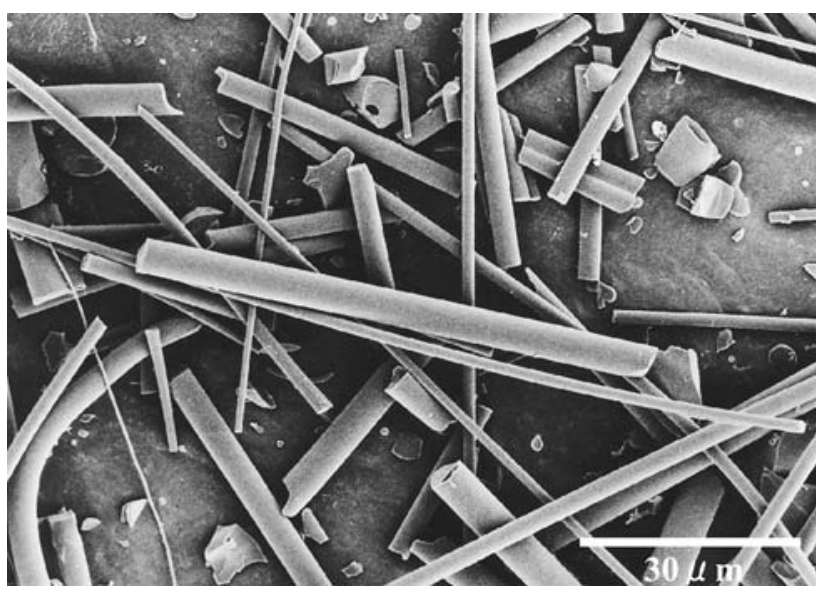

Fig. 1 Electron microscopic image of fiber before generation $(\times 1000)$ 
filtered air. The temperature in the chamber was kept at $22^{\circ} \mathrm{C}$ and $40 \%$ humidity.

The experiment was conducted by exposing the rats to the RW fibers continuously for $3 \mathrm{~h}$ a day for five consecutive days. The target airborne fiber concentration was set to $30 \mathrm{mg} / \mathrm{m}^{3}$ in mass concentration and $50 \pm 10$ fibers $/ \mathrm{cm}^{3}$ in fiber concentration. Each day during the experimental period, the rats fixed in the upper rat holders of the main chamber were replaced by the rats in the lower rat holders, rotating the positions among the upper and lower rat holders. During the exposure period, the fiber concentration in the chamber was monitored five times every day $(30,60,90,120$, and $150 \mathrm{~min}$ after the start of the exposure experiment) by the following airborne fiber monitoring methods in addition to continuous monitoring by a digital dust meter (Shibata Corp., Tokyo). To monitor the airborne fiber concentration in the nose-only exposure chamber, air samplings were performed using membrane filters (Nihon Millipore K. K., Tokyo, $0.8 \mu \mathrm{m}$ pore diameter and $25 \mathrm{~mm}$ diameter; referred to as "MF"), T60A20 filters (Tokyo Dylec Corp., Tokyo, 25 mm diameter; referred to as "T60A20"), and Nuclepore filters (Nomura Micro Science Co., Ltd., Kanagawa, $0.2 \mu \mathrm{m}$ pore diameter, $25 \mathrm{~mm}$ diameter; referred to as "NF") set in a plastic holder. During a specified period of time, sample fibers were collected on MF for $1 \mathrm{~min}, \mathrm{~T} 60 \mathrm{~A} 20$ for $10 \mathrm{~min}$, and NF for 5 min using an electric suction pump (GilAir-5: Gilian, USA), and the fiber concentration was confirmed by measuring the fiber numbers (fiber/ $\mathrm{cm}^{3}$ ) and mass concentration $\left(\mathrm{mg} / \mathrm{m}^{3}\right)$ using respective filters. Fibers collected on MF with an aspect ratio (length-to-width ratio) of 3 or higher were measured by phase-contrast microscopy following the criteria for fiber measurement [14]. To measure the mass concentration $\left(\mathrm{mg} / \mathrm{m}^{3}\right)$, weight of T60A20-collected airborne fibers was measured using an electronic balance, comparing with the weight before sampling.

Shortly after the fifth day of exposure, five rats (mean weight $180 \mathrm{~g}$ ) were sacrificed (the shortly-after group). Five rats each were also sacrificed 1 week (the 1-weekafter group), 2 weeks (the 2-weeks-after group), and 4 weeks (the 4-weeks-after group) after the end of the exposure period. The body weights of the rats were measured once a week, and their appearance and condition were intermittently monitored for any change during and after the exposure period.

Measurement of fibers in rat lungs

Under anesthesia with pentobarbital $(0.15 \mathrm{mg} / \mathrm{kg}$ body weight), rats were sacrificed by bleeding from the abdominal aorta and their lungs were resected. The resected lungs were stored at low temperature $\left(-20^{\circ} \mathrm{C}\right)$. Subsequently, the lung tissues were thawed at room temperature, minced, and lyophilized to reduce their weight to a specified level. The weight after lyophilization was regarded as the weight of dried lungs. The lyophilized lungs of about $17 \mathrm{mg}$ were incinerated in a low-temperature asher (Plasma Asher LTA102, Yanaco Corp., Kyoto) for $24 \mathrm{~h}$.

After incineration, distilled water that had been filtered with Minisart (Sartorius K.K., Tokyo) was added to the weighing bottle to suspend fibers, and the fibers were collected on an MF (pore diameter $0.22 \mu \mathrm{m}$ ) using a suction filter and allowed to dry. The dried filter was put on a slide glass, and treated with acetone vapor using Quick Fix, making it transparent. At least $200 \mathrm{RW}$ fibers were counted on each filter sample using a phase-contrast microscope (BX41, Olympus Corp., Tokyo). Fibers to be counted were those with aspect ratio of 3 or higher. Win Roof (image analysis software, Mitani Corp., Tokyo) was used to obtain the number of fibers, distinguishing the length $(L)$ as $L \leq 5 \mu \mathrm{m}, 5 \mu \mathrm{m}<L \leq 20 \mu \mathrm{m}$, and $L>20 \mu \mathrm{m}$. Among the fibers counted, the concentration of fibers $(L>5 \mu \mathrm{m}$ and width $<3 \mu \mathrm{m})$ in accordance with World Health Organization (WHO) method (referred to as "WHO fibers") was also measured [11]. Then, the fiber number was converted to the fiber number per weight of dried lung tissue. The half-life of fibers in the rat lungs was calculated assuming that the geometric mean of the total fiber number divided by the total lung weight (fibers/mg) in the lungs of the shortly-after group was $100 \%$ [15].

\section{Measurement of fiber sizes}

To measure the sizes of fibers (length and width) in the air and in the lungs, fibers within the measurable visual range and with an aspect ratio of 3 or higher were measured using a phase-contrast microscope at $400 \times$ magnification. At least 200 fibers, $0.36 \mu \mathrm{m}$ or longer, were counted for each rat.

Statistical analysis

The geometric mean and geometric standard deviation of the total fiber number in length and width were calculated. Moreover, to measure the length and width, a minimum of 200 fibers obtained in the two experiments, which had entered the rats' lungs, were used for each rat. The geometric mean for a group of five rats was then calculated. One-way analysis of variance and multiple comparisons by Scheffe's test were performed.

\section{Results}

Monitoring of fiber concentration in exposure chamber

Table 1 shows the fiber concentration in the exposure chamber in each experiment. The mean (SD) values of the 
Table 1 Fiber concentrations in exposure chamber

\begin{tabular}{|c|c|c|c|c|c|c|}
\hline & \multicolumn{3}{|l|}{ First experiment } & \multicolumn{3}{|l|}{ Second experiment } \\
\hline & $\begin{array}{l}\text { Digital dust meter } \\
\text { (count/min) }\end{array}$ & $\begin{array}{l}\text { Fiber } \\
\text { concentration } \\
\left(\mathrm{f} / \mathrm{cm}^{3}\right)\end{array}$ & $\begin{array}{l}\text { Weight } \\
\text { concentration } \\
\left(\mathrm{mg} / \mathrm{m}^{3}\right)\end{array}$ & $\begin{array}{l}\text { Digital dust meter } \\
\text { (count/min) }\end{array}$ & $\begin{array}{l}\text { Fiber } \\
\text { concentration } \\
\left(\mathrm{f} / \mathrm{cm}^{3}\right)\end{array}$ & $\begin{array}{l}\text { Weight } \\
\text { concentration } \\
\left(\mathrm{mg} / \mathrm{m}^{3}\right)\end{array}$ \\
\hline Day $1(n=5)$ & $9861(274)$ & $81.0(19.5)$ & $30.0(6.2)$ & $9550(134)$ & $39.8(14.3)$ & $24.4(3.6)$ \\
\hline Day $2(n=5)$ & 9237 (197) & $72.8(5.0)$ & $27.0(7.1)$ & $9824(585)$ & $77.4(27.4)$ & $30.8(4.6)$ \\
\hline Day $3(n=5)$ & 9247 (97) & $81.3(14.9)$ & $33.2(7.8)$ & 10419 (215) & $69.9(20.1)$ & $37.2(5.4)$ \\
\hline Day $4(n=5)$ & $9313(154)$ & $65.0(26.2)$ & $29.2(2.3)$ & 9636 (1697) & $63.1(21.6)$ & $24.4(6.2)$ \\
\hline Day $5(n=5)$ & $9137(81)$ & $86.8(12.0)$ & $30.4(4.3)$ & $10851(458)$ & $68.5(20.1)$ & $37.2(5.0)$ \\
\hline Mean $(n=25)$ & 9257 (182.4) & $75.1(18.0)$ & $30.0(5.7)$ & $10042(966)$ & $63.7(23.3)$ & 30.5 (7.4) \\
\hline
\end{tabular}

Arithmetic mean (standard deviation)

Fig. 2 a Distribution of length of fibers generated (inside the chamber). b Distribution of width of fibers generated (inside the chamber)
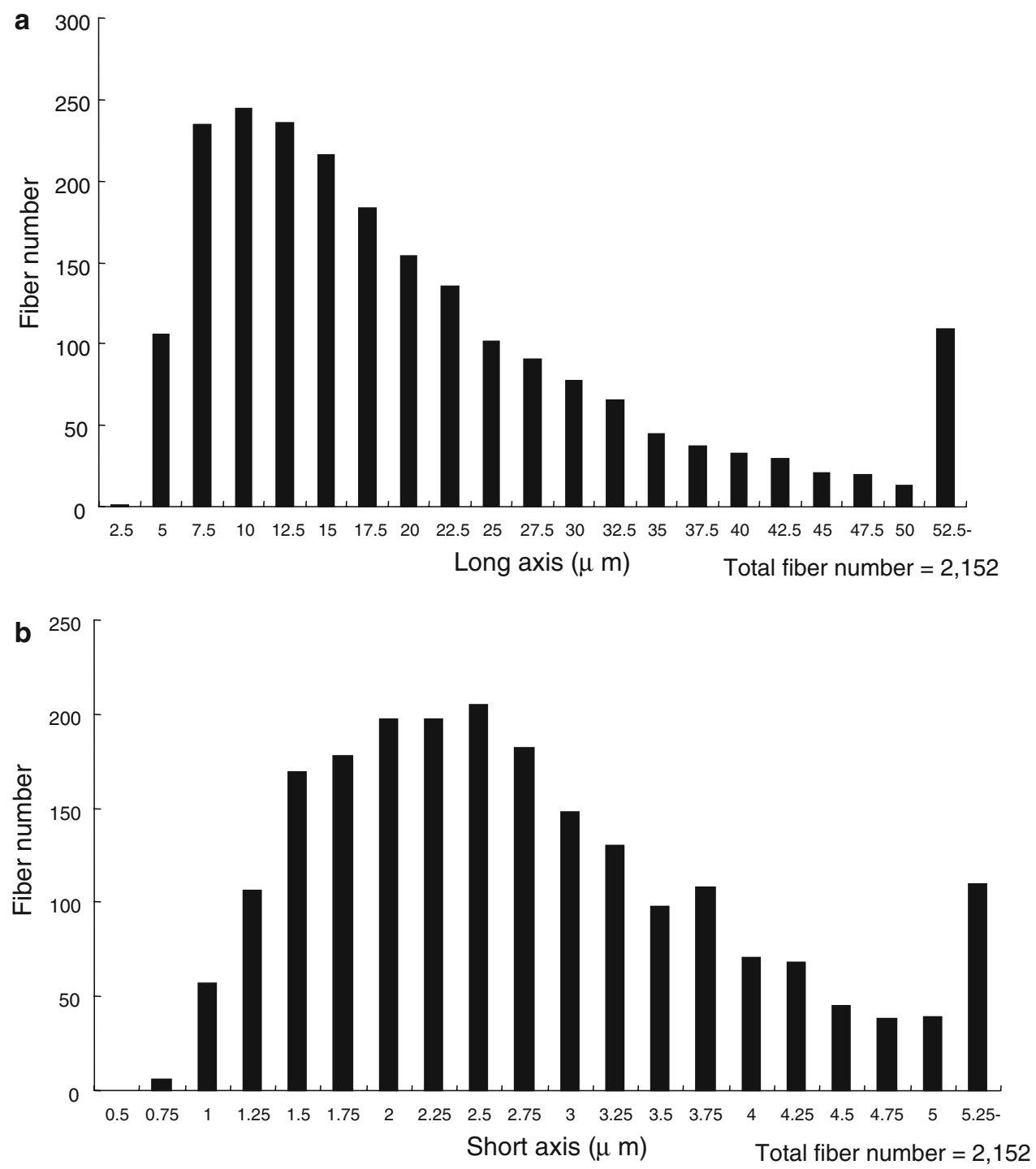

count obtained by the digital dust meter for the first and second experiments (5 days each) were 9,257 (182.4) and 10,042 (966) counts/min. The mean fiber concentrations (SD) in the exposure chamber were 75.1 (18.0) and 63.7
(23.3) fibers $/ \mathrm{cm}^{3}$, and similarly, the mean weight concentrations (SD) were $30.0(5.7) \mathrm{mg} / \mathrm{m}^{3}$ and $30.5(7.4) \mathrm{mg} / \mathrm{m}^{3}$, respectively. Fig. 2 shows the frequency distribution (histogram) of the length and width of fibers inside the 
exposure chamber, in which the geometric mean (GSD) of the length was $15.49(2.02) \mu \mathrm{m}$ and that of the width was 2.44 (1.59) $\mu \mathrm{m}$.

Intrapulmonary fiber deposition rate

The total number of RW fibers inhaled by rats during the experimental period was calculated by the following equation:

Total number of RW fibers inhaled

$=$ fiber concentration $\times$ respiratory volume

$\times$ duration of exposure.

The respiratory volume in the rats was calculated by the following equation [16]:

Respiratory volume $(\mathrm{mL} / \mathrm{min})$
$=2.1 \times[\text { body weight }(\mathrm{g})]^{0.75}$.

Since the mean body weight of the rats was $131 \mathrm{~g}$, the respiratory volume was calculated as follows:

$2.1 \times[131(\mathrm{~g})]^{0.75}=81.32 \mathrm{~mL} / \mathrm{min}$.

RW fiber concentration in the exposure chamber, as calculated according to the rules in the Guidebook for Working Environment Measurement [14], was 70.6 fibers/ $\mathrm{cm}^{3}$. Since the rats were exposed for $3 \mathrm{~h}$ daily for five consecutive days, the total number of RW fibers inhaled was calculated as follows:

Total number of RW fibers inhaled

$=70.6$ fibers $/ \mathrm{cm}^{3} \times 81.32 \mathrm{~mL} / \mathrm{min} \times 3 \times 60 \mathrm{~min} \times 5$

$=51.67 \times 10^{5}$ fibers.
Since the total fiber number inside the lungs corresponding to this number was found to be $7.09 \times 10^{5}$ fibers shortly after exposure, the intrapulmonary fiber deposition rate was calculated as follows:

$7.09 \times 10^{5} / 51.67 \times 10^{5}=0.137$.

Thus, the intrapulmonary fiber deposition rate was $13.7 \%$

Changes in fiber number in both lungs

Table 2 and Fig. 3 show the numbers of RW fibers accumulated in the lungs and their proportions, based on the assumption that the value shortly after exposure was $100 \%$.

The mean of the total fiber number of both dried lungs tended to decrease during the period from shortly after exposure to 4 weeks after exposure. Although the decreasing rates of the numbers of fibers with a length of $5 \mu \mathrm{m}$ or less $(L \leq 5 \mu \mathrm{m})$, those longer than $5 \mu \mathrm{m}$ but shorter than or equal to $20 \mu \mathrm{m}(5 \mu \mathrm{m}<L \leq 20 \mu \mathrm{m})$, and WHO fibers $(L>5 \mu \mathrm{m}$ and $W<3 \mu \mathrm{m})$ were low at a certain point, the number of fibers in the 4-weeks-after group was smaller than that in the shortly-after group $(100 \%)$. At the same time, fibers longer than $20 \mu \mathrm{m}$ $(L>20)$ tended to decrease relatively quickly during the period from shortly after exposure to 4 weeks after exposure. Multiple comparison by Scheffe's test showed that the numbers of total fibers, those with $5 \mu \mathrm{m}<L \leq 20 \mu \mathrm{m}$, those with $L>20 \mu \mathrm{m}$, and WHO fibers in the 4-weeksafter group decreased significantly compared with the shortly-after group $(P<0.05)$.

Table 2 Fiber numbers in lungs and their proportions

\begin{tabular}{|c|c|c|c|c|c|c|c|c|c|c|}
\hline \multirow[t]{2}{*}{$\begin{array}{l}\text { Sacrificed rat } \\
\text { group }\end{array}$} & \multicolumn{2}{|l|}{ Total fibers } & \multicolumn{2}{|c|}{$\begin{array}{l}\text { Fibers shorter than } \\
\text { or equal to } 5 \mu \mathrm{m} \\
(L \leq 5 \mu \mathrm{m})\end{array}$} & \multicolumn{2}{|c|}{$\begin{array}{l}\text { Fibers longer than } \\
5 \mu \mathrm{m} \text { and shorter than } \\
\text { or equal to } 20 \mu \mathrm{m} \\
(5 \mu \mathrm{m}<L \leq 20 \mu \mathrm{m})\end{array}$} & \multicolumn{2}{|c|}{$\begin{array}{l}\text { Fibers longer than } \\
20 \mu \mathrm{m}(L>20 \mu \mathrm{m})\end{array}$} & \multicolumn{2}{|l|}{ WHO fibers } \\
\hline & $\begin{array}{l}\text { Geometric } \\
\text { mean (GSD) }\end{array}$ & $\%$ & $\begin{array}{l}\text { Geometric } \\
\text { mean (GSD) }\end{array}$ & $\%$ & $\begin{array}{l}\text { Geometric } \\
\text { mean (GSD) }\end{array}$ & $\%$ & $\begin{array}{l}\text { Geometric } \\
\text { mean (GSD) }\end{array}$ & $\%$ & $\begin{array}{l}\text { Geometric } \\
\text { mean (GSD) }\end{array}$ & $\%$ \\
\hline Shortly-after group & $9.43(1.13)$ & 100.0 & $2.12(1.24)$ & 100.0 & $6.08(1.13)$ & 100.0 & $1.21(1.14)$ & 100.0 & $7.09(1.12)$ & 100.0 \\
\hline 1-Week-after group & $7.42(1.35)$ & 78.7 & $2.04(1.50)$ & 96.3 & $4.75(1.34)$ & 78.2 & $0.54(1.83)$ & 44.9 & $5.20(1.36)$ & 73.3 \\
\hline 2-Weeks-after group & 7.68 (1.17) & 81.5 & $2.12(1.16)$ & 100.3 & $5.07(1.21)$ & 83.4 & $0.42(1.73)$ & 34.7 & $5.45(1.20)$ & 76.9 \\
\hline 4-Weeks-after group & $5.05(1.23)^{\mathrm{a}, \mathrm{c}}$ & 53.6 & $1.59(1.48)$ & 74.9 & $3.13(1.24)^{\mathrm{a}, \mathrm{c}}$ & 51.5 & $0.22(2.27)^{\mathrm{a}}$ & 17.9 & $3.38(1.25)^{\mathrm{a}, \mathrm{b}, \mathrm{c}}$ & 47.7 \\
\hline
\end{tabular}

Geometric mean: $\times 10^{5} /$ lung, WHO fiber: length $>5 \mu \mathrm{m}$ and width $<3 \mu \mathrm{m}$

$\%$ : percentage assuming the value of the shortly-after group to be $100 \%$

$n=5, L$ length of fiber $(\mu \mathrm{m})$

GSD geometric standard deviation

${ }^{\text {a }}$ Comparison with shortly-after group $(P<0.05)$

${ }^{\mathrm{b}}$ Comparison with 1 -week-after group $(P<0.05)$

${ }^{c}$ Comparison with 2-weeks-after group $(P<0.05)$ 
Fig. 3 Percentages of fibers in lungs: filled square shortly-after group, striped bar 1-week-after group, dotted square 2-weeksafter group, open square 4-weeks-after group.

Percentage, assuming the value of the shortly-after group to be $100 \% . n=5, L$ Length of fiber $(\mu \mathrm{m})$
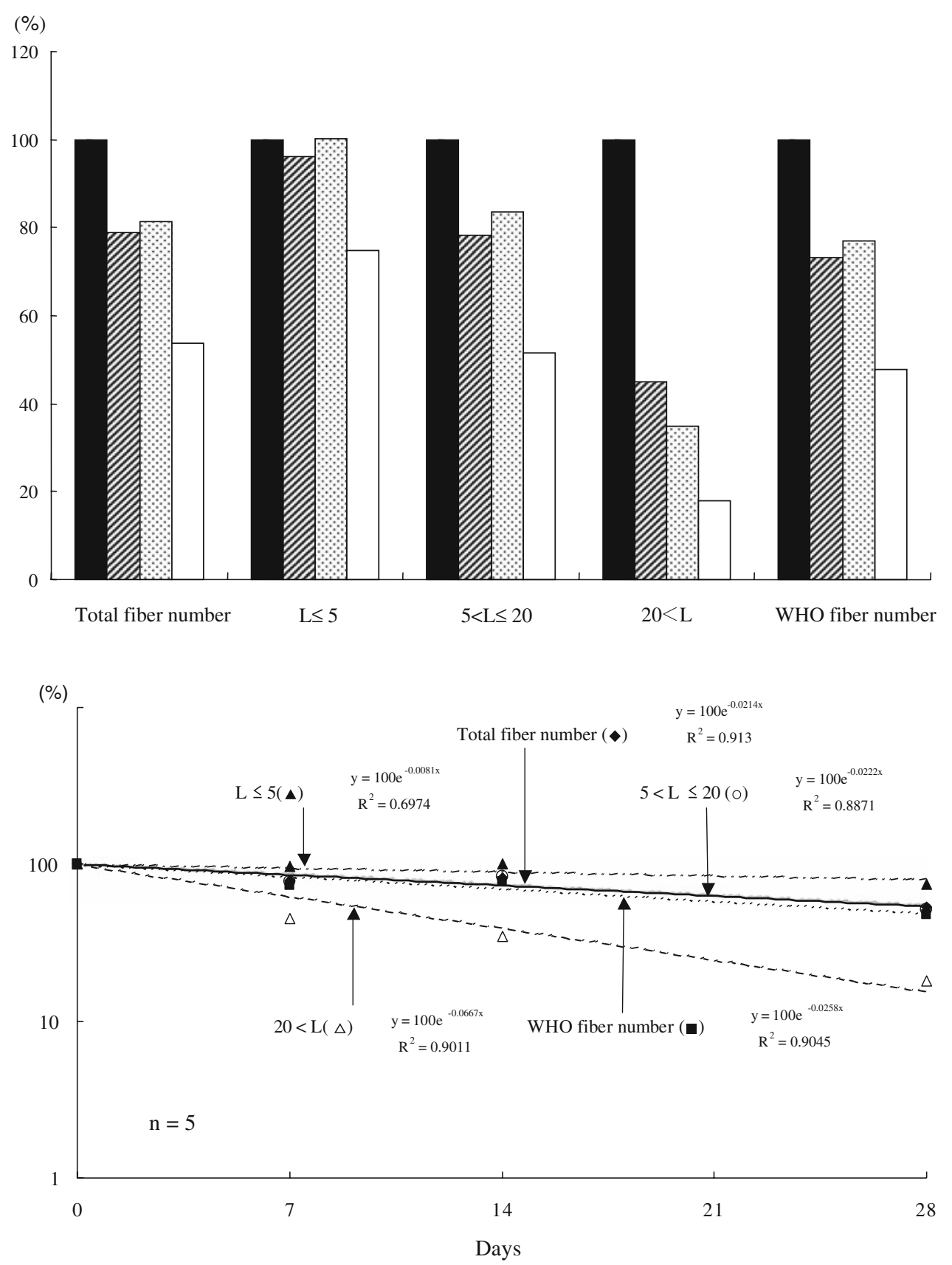

Fig. 4 Clearance of RW fibers from rat lungs $(\%)$, calculated assuming that the value of the shortly-after group is $100 \%$
Half-life of fibers

Data obtained by plotting the number of fibers in the rat lungs against measurement time on a logarithm scale showed linear (i.e., exponential) decreases. Therefore, the half-life was calculated from the one-compartment model as shown in Fig. 4. The half-lives based on this calculation were 32 days for the total fiber number, 86 days for $L \leq 5 \mu \mathrm{m}$, 31 days for $5 \mu \mathrm{m}<L \leq 20 \mu \mathrm{m}, 10$ days for $L>20 \mu \mathrm{m}$, and 27 days for WHO fibers. The half-life of the longer fibers $(L>20 \mu \mathrm{m})$ tended to be shorter than that of shorter fibers $(L \leq 20 \mu \mathrm{m})$.
Distribution and changes of fiber size

Table 3 shows the changes in the length and width of the intrapulmonary fibers in the shortly-after, and 1-, 2- and 4-weeks-after groups expressed by the geometric mean, with geometric standard deviation in parentheses.

The average length was $8.58 \mu \mathrm{m}$ in the shortly-after group, and decreased significantly in the other three groups, being $6.87 \mu \mathrm{m}$ in the 4-weeks-after group $(P<0.05)$. Compared with the 1 -week-after group, it decreased significantly in the 4-weeks-after group $(P<0.05)$. 
Table 3 Changes in length and width of fibers in lungs

\begin{tabular}{|c|c|c|}
\hline \multirow[t]{2}{*}{ Sacrificed rat group } & \multicolumn{2}{|c|}{ Geometric mean (GSD) } \\
\hline & Length $(\mu \mathrm{m})$ & Width $(\mu \mathrm{m})$ \\
\hline Shortly-after group & $8.58(1.94)$ & $1.26(1.43)$ \\
\hline 1-week-after group & $7.53(1.87)^{\mathrm{a}}$ & $1.18(1.39)^{\mathrm{a}}$ \\
\hline 2-weeks-after group & $7.35(1.80)^{\mathrm{a}}$ & $1.17(1.37)^{\mathrm{a}}$ \\
\hline 4-weeks-after group & $6.87(1.75)^{\mathrm{a}, \mathrm{b}}$ & $1.14(1.32)^{\mathrm{a}}$ \\
\hline
\end{tabular}

Geometric mean (GSD geometric standard deviation), $n=5$

${ }^{a}$ Comparison with shortly-after group $(P<0.05)$

${ }^{\mathrm{b}}$ Comparison with 1 -week-after group $(P<0.05)$

The average width was $1.26 \mu \mathrm{m}$ in the shortly-after group, and decreased significantly in the other three groups, being $1.14 \mu \mathrm{m}$ in the 4 -weeks-after group $(P<0.05)$.

\section{Discussion}

Fiber size and biopersistence of asbestos or MMVF have been shown in many previous epidemiological, physicochemical, and animal studies to be important factors in terms of their adverse health effects, especially carcinogenicity. With regard to inhaled fibers, these previous studies reported that, the thinner and longer the fiber is, the more carcinogenic it becomes. In addition, regarding biopersistence, fibers that remain in the lung tissues for a long period of time without being degraded or transferred are considered to be more carcinogenic [15]. It is said that fibers with a length of $20 \mu \mathrm{m}$ or longer having a long halflife tend to cause fibrosis or cancer because of their low degradation in the living body $[11,15]$. Biopersistence is related to the quantity of fibers that remain inside the lungs (intrapulmonary fiber retention quantity). Intrapulmonary fiber retention quantity is the number of fibers that have entered the lungs and stayed, minus the volume excreted by the lungs' self-cleansing action. It shows the amount that is present inside the lungs due to exposure. The intrapulmonary fiber retention quantity is based on the retentionexcretion balance: if the intrapulmonary retention volume is too large for excretion to catch up, or if excretion fails to work properly, this quantity increases, inducing pulmonary damage [11].

The nose-only inhalation exposure system used in this experiment is an improved version of the traditional type in that a subchamber was set up just before the exposure chamber. There are two advantages to this approach. The first is that the subchamber can control the concentration of generated RW fibers, enabling a specified concentration to be supplied into the exposure chamber. The second is that the subchamber can select similar-sized fibers and supply them to the main exposure chamber. As long and thick fibers that cannot be inhaled by rats precipitate in the subchamber, it is possible to supply only inhalable fibers to the exposure chamber. This method also allowed RW fibers to be generated constantly at a relatively high concentration for a specified period of time. Consequently, RW fibers were generated at almost the same concentration, because they were generated nearly at the target fiber and weight concentrations initially intended, although there were some daily fluctuations.

Hammad et al. [17] reported that the fiber deposition rate was almost in the range of $1-7 \%$ in rats necropsied on day 5 after being exposed to fibers for $6 \mathrm{~h}$ daily for five consecutive days, while the fiber deposition rate in our study, shortly after the end of exposure, after being exposed for $3 \mathrm{~h}$ daily for five consecutive days, was $13.7 \%$, although it is not possible to make a direct comparison between the two studies. In future studies, we plan to measure the deposition rate under the same conditions as those in the previous study [17] so that the results can be comparatively reviewed.

The total fiber number and fiber numbers counted according to length tended to decrease with time from shortly after exposure to the end of the fourth week. In preceding studies, manmade vitreous fibers of all sizes decreased by $30-50 \%$ during 30 days after exposure [18, 19]. Fibers that are inhaled and precipitated in the lungs show different mechanisms for clearance depending on the site of precipitation. Fibers deposited in the bronchioles are transferred to the pharynx by mucociliary movements and discharged from the body [11, 14]. It is presumed that fibers deposited in the alveoli are excreted by either (a) being dissolved by body fluid or phagocytosed and digested by alveolar macrophages (chemical excretion) or (b) being transferred to the airway or lymphatic tissue by alveolar macrophages, and discharged from the body (physical excretion). Whether a fiber is phagocytosed or not depends on its length. Fibers with a length $20 \mu \mathrm{m}$ or shorter seem to be phagocytosed and digested by alveolar macrophages $[11,15]$, while those with a length longer than $20 \mu \mathrm{m}$ cannot be completely phagocytosed by alveolar macrophages. These fibers are presumed to be either (a) dissolved by body fluid or (b) folded transversely and crushed to be shortened in length and then phagocytosed and digested by alveolar macrophages, or taken into pulmonary epithelial cells and transferred to lymphatic tissue, thus being discharged from the body [11, 15]. The fiber number is believed to be decreased by these mechanisms. Moreover, the rate of decrease in the number of fibers with a length shorter than $20 \mu \mathrm{m}$ slowed down in the 1- and 2-weeksafter groups. A possible reason for this phenomenon is that fibers longer than $20 \mu \mathrm{m}$ were dissolved by extracellular fluid and folded transversely with the fibers being crushed, thus increasing the number of shorter fibers (shorter than 
$20 \mu \mathrm{m})$ and, as a result, increasing the rate of accumulation in a number of indicators including the total fiber number [11].

The half-life was especially short (10 days) for long fibers with lengths of $20 \mu \mathrm{m}$ or longer. In a preceding study, the half-life was reported to be 111 days for WHO fibers of RW ( $L>5 \mu \mathrm{m}$ and $W<3 \mu \mathrm{m}$ ) and 53 days for fibers with a length of $20 \mu \mathrm{m}$ or longer [18]. The half-life of fibers longer than $20 \mu \mathrm{m}$ was shorter than those of fibers of the other sizes in this study. The reason seems to be as follows: the number of fibers longer than $20 \mu \mathrm{m}$ decreased rapidly, resulting in a short half-life, because they were folded transversely and became shorter. In contrast, the number of fibers $20 \mu \mathrm{m}$ or shorter did not decrease rapidly and thus the half-life was longer, because longer fibers were folded and became shorter, which resulted in an increased number of fibers $20 \mu \mathrm{m}$ or shorter, even though the number of shorter fibers was reduced by phagocytosis by macrophages.

The distributions of fiber sizes (length and width) of generated fibers were significantly different from those of fibers in the lungs. It has been reported that fibers inhaled through the rat nose are mostly less than $80 \mu \mathrm{m}$ in length and less than $1.5 \mu \mathrm{m}$ in width [20]. Consequently, the difference observed in this study may indicate size separation due to inhalation by rats. After fibers are inhaled into the lungs, fiber sizes (both length and width) tended to decrease with time in comparison with those shortly after exposure. In a preceding study on RW conducted in Denmark, the mean length decreased from about $9 \mu \mathrm{m}$ shortly after exposure to about $8 \mu \mathrm{m}$ in the fourth week [21]. The mean width also decreased from about $0.7 \mu \mathrm{m}$ shortly after exposure to about $0.6 \mu \mathrm{m}$ in the fourth week [21]. In another study on RW conducted in Denmark, the mean length decreased from about $11 \mu \mathrm{m}$ shortly after exposure to about $10 \mu \mathrm{m}$ in the fourth week, and the mean width decreased from about $0.8 \mu \mathrm{m}$ shortly after exposure to about $0.6 \mu \mathrm{m}$ in the fourth week [18]. The reason for the reduction in mean length and width seems to be as follows: fibers $20 \mu \mathrm{m}$ or shorter were phagocytosed by alveolar macrophages, as stated earlier, while those longer than $20 \mu \mathrm{m}$ were either (a) captured in the trachea and discharged from the body by mucociliary movement or (b) dissolved by body fluid or folded, shortened, and phagocytosed by macrophages [15]. The length seems to have decreased through the same mechanism of fiber number reduction as described earlier. The width, meanwhile, is believed to have decreased as a result of dissolution by body fluid.

Another report stated that the reduction in fiber size by body fluid was caused by a change in chemical composition [21]. In that study the changes in chemical composition of MMVF were observed over a period of a year and fiber sizes were assumed to decrease uniformly [21]. In a study on glass wool, it was shown that oxides of alkali metals and alkaline-earth metals decreased and chemical constituents of fibers dissolved unevenly. Thereafter, the fibers were folded transversely, and phagocytosed by alveolar macrophages, reducing the length and width [21].

In this study, we examined the behavior of RW in the lungs to evaluate its persistence in the lungs by a short-term nose-only inhalation exposure study in rats. It is impossible, strictly speaking, to make a direct comparison between the results of a long-term observation and those of a shortterm observation, as was the case in the present study. Based on the recognition of this limitation, the present study seems to suggest the safety of RW fibers. At present we are conducting a long-term nasal exposure inhalation experiment to examine the pathological effects of RW, such as the long-term persistence of RW in the lungs, carcinogenicity, and pulmonary fibrosis, and plan to assess the safety of RW further, taking the results of the present study also into consideration.

Acknowledgments We would like to express our deepest gratitude to Dr. Hideki Enjo, Department of Preventive Medicine and Public Health, Kitasato University School of Medicine, for supporting us, guiding us, and proofreading the manuscript. We would also like to thank Ms. Yumiko Sugiura, Ms. Yoko Inoue, Ms. Yumi Komatsu, Ms. Michiyo Koyama, and Ms. Asuka Yamamoto, Department of Preventive Medicine and Public Health, Kitasato University School of Medicine, and Mr. Shichiro Miyazawa and Ms. Noriko Nemoto, Electron Microscopy Center, for their meticulous advice and encouragement.

\section{References}

1. Doll R. Mortality from lung cancer in asbestos workers. Br J Ind Med. 1993;50:485-90.

2. Planning Division, Air Quality Bureau, Ministry of the Environment ed. All about asbestos and zeolite. Kawasaki: Japan Environmental Sanitation Center 1987: 1-476.

3. Morinaga K, Kohyama N. Healthcare for Workers Handling Asbestos. Tokyo: The Occupational Health Promotion Foundation; 1993. p. 141-66.

4. Berry G. Mortality of workers certified by pneumoconiosis medial panels as having asbestosis. Br J Ind Med. 1981;38:130-7.

5. Gormley IP, Bolton RE, Brown GM, et al. Some observations on the in vitro cytotoxicity of chrysotile prepared by the wet dispersion process. Environ Health Perspect. 1983;51:35-9.

6. Koshi K, Sakabe H. Effect of asbestos dusts on the cultured macrophages. Ind Health. 1972;10:16-23.

7. Planning Division, Air Quality Bureau, Ministry of the Environment ed. All about Asbestos Substitutes. Kawasaki: Japan Environmental Sanitation Center 1989: 106-9.

8. McConnell EE, Axten C, Hesterberg TW, et al. Studies on the inhalation toxicology of two fiberglasses and amosite asbestos in the Syrian golden hamster. Part II. Results of chronic exposure. Inhal Toxicol. 1999;11:785-835.

9. Davies R. The effect of mineral fibers on macrophages. IARC Sci Publ. 1980;30:419-25.

10. Brown RC, Chamberlain M, Skidmore JW. In vitro effects of man-made mineral fibers. Ann Occup Hyg. 1979;22:175-9. 
11. Man-made Viterous Fibers. IARC Monographs on the Evaluation of Carcinogenic Risks to Humans, vol. 81. Lyon: IARC; 2002.

12. Kohyama N, Tanaka I, Tomita M, et al. Preparation and characteristics of standard references samples of fibrous minerals for biological experiments. Ind Health. 1997;35:415-32.

13. Kudo Y, Shibata K, Miki T, et al. Behavior of new type of rock wool (HT wool) in lungs after exposure by nasal inhalation in rats. Environ Health Prev Med. 2005;10:239-48.

14. The Environmental Improvement Office, Industrial Safety and Health Department, Ministry of Labor ed. Mineral Dusts. Guidebook for Working Environment Measurement I, Tokyo: Japan Association for Working Environment Measurement 2000: $167-80$.

15. Hesterberg TW, Hart GA. Synthetic vitreous fibers: a review of toxicology research and its impact on hazard classification. Crit Rev Toxicol. 2001;31:1-53.

16. Tanaka I. Particle deposition and clearance in respiratory organs in small animals. J Aerosol Res. 1988;3:16-23. (in Japanese).
17. Hammad Y, Diem J, Craighead J, et al. Deposition of inhaled man-made mineral fibers in the lungs of rats. Ann Occup Hyg. 1982;26:179-87.

18. Hesterberg TW, Chase G, Axten C, et al. Biopersistence of synthetic vitreous fibers and amosite asbestos in the rat lung following inhalation. Toxicol Appl Pharmacol. 1998;151:262-75.

19. Musselman RP, Miiller WC, Eastes W, et al. Biopersistence of man-made vitreous fibers and crocidolite fibers in rat lungs following short-term exposures. Environ Health Perspect. 1994; 102(suppl 5):139-43.

20. McConnell EE, Kamstrup O, Musselman RP, et al. Chronic inhalation study of size-separated rock and slag wool insulation fibers in Fischer 344/N rats. Inhal Toxicol. 1994;6:571-614.

21. Hesterberg TW, Miiller WC, Musselman RP, et al. Biopersistence of man-made vitreous fibers and crocidolite asbestos in the rat lung following inhalation. Fundam Appl Toxicol. 1996; 29:267-79. 